\title{
Análise dos Parâmetros de Polaridade Negativa do Processo MAG-PV sobre Distorções Angulares
}

\author{
Arnaldo Ruben Gonzalez ${ }^{1}$ (D) , Ivan Guerra Machado ${ }^{2}$ (D) , Augusto Tomazi ${ }^{3}$ \\ 1 Universidade Federal do Rio Grande do Sul - UFRGS, Laboratório de Soldagem \& Técnicas Conexas, Programa de Pós-graduação em Engenharia Mecânica - \\ PROMEC, Porto Alegre, RS, Brasil \\ 2 Universidade Federal do Rio Grande do Sul - UFRGS, Laboratório de Soldagem \& Técnicas Conexas, Programa de Pós-graduação em Engenharia de Minas, \\ Metalúrgica e de Materiais - PPGE3M, Porto Alegre, RS, Brasil \\ ${ }^{3}$ Universidade Federal do Rio Grande do Sul - UFRGS, Departamento de Engenharia Mecânica - DEMEC, Laboratório de Soldagem \& Técnicas Conexas, Porto \\ Alegre, RS, Brasil
}

Como citar: Gonzalez AR, Machado IV, Tomazi A. Análise dos parâmetros de polaridade negativa do processo MAG-PV sobre distorções angulares. Soldagem \& Inspeção. 2020;25:e2503. https://doi.org/10.1590/0104-9224/SI25.03

\begin{abstract}
Resumo: $O$ objetivo deste trabalho é entender a influência da polaridade negativa no processo de soldagem MAG Polaridade Variável, em particular para aplicações de revestimento. Para isso foram escolhidos individualmente os parâmetros da polaridade negativa e analisados em relação à distorção angular da junta soldada, utilizando aço ao carbono como metal base e aço inoxidável como metal de adição. Foi aplicada a metodologia de superfície de resposta e o projeto de experimentos Box-Behnken no planejamento e execução do experimento, variando três fatores: tempo de corrente de base positiva, tempo de corrente negativa e corrente negativa, em três níveis cada um. Os três parâmetros principais avaliados apresentaram efeito significativo sobre a distorção angular. O menor valor de distorção angular foi obtido para o tempo da corrente de base positiva (15 ms), tempo de corrente negativa (15 ms) e intensidade de corrente negativa (-50 A). Todos eles apresentaram efeitos significativos no resultado final, responsável pelo menor valor de distorção angular, aproximadamente 0,02748 rad. Posteriormente, foi realizada a validação do modelo matemático para o alvo de menor valor da distorção angular estimado, o erro (\%) entre os resultados da distorção angular estimada mediante a equação de regressão e o experimento foi de $3,65 \%$.
\end{abstract}

Palavras-chave: MAG polaridade variável; Parâmetros negativos, Soldagem de revestimento; Distorção angular; Projeto Box-Behnken.

\section{Analysis of Negative Polarity Parameters of the MAG-VP Process on Angular Distortions}

\begin{abstract}
It is intended to understand the influence of negative polarity on MAG variable polarity manufacturing process, in particular for coating applications, for that the negative polarity parameters were chosen individually and evaluated according to the angular distortion of the welded joint using carbon as base metal and stainless steel as filler metal. The response surface methodology and the Box-Behnken design of experiments were applied in the design and execution of the experiment varying three factors: base current time, negative current time and negative current, in three levels each. The three main parameters evaluated had a significant effect on angular distortion. The lowest angular distortion value was obtained with a positive base current time of $15 \mathrm{~ms}$, negative current time of $15 \mathrm{~ms}$ and negative current intensity of $-50 \mathrm{~A}$. All of which had significant effects on the final result, responsible for the lowest angle of distortion of approximately 0,02748 rad. Subsequently, a validation of the mathematical model was performed with the lowest estimated angular distortion value. The error (\%) between the estimated angular distortion through the regression equation and the experiment was 3.65\%.
\end{abstract}

Key-words: MAG variable polarity; Negative parameters; Coating welding; Angular distortion; Box-Behnken design.

\section{Introdução}

O processo de soldagem consolidou-se devido à necessidade de unir componentes metálicos permanentemente em diversas indústrias como as dos ramos naval, automotivo, petroquímico, militar, e muitas outras.

Atualmente, os processos de soldagem ao arco elétrico e fusão de materiais metálicos são os mais difundidos industrialmente. Na manutenção de equipamentos sempre há custos relacionados ao tempo de parada do equipamento o que torna importante a taxa de deposição do processo de soldagem. Em particular no revestimento superficial, é necessário obter a 
menor penetração e mínima diluição, aliada à menor distorção da estrutura ou junta soldada. Podem ser utilizados os processos de soldagem MIG/MAG Curto Circuito Controlado, MIG/MAG Pulsado e MIG/MAG Polaridade Variável para proporcionar controle acurado da penetração, diluição e distorção. Dentre eles, o último proporciona o melhor controle de penetração, menor diluição e uma menor distorção [1].

No processo MIG/MAG pulsado há formação de uma gota de metal fundido na ponta do eletrodo em cada período de pulso. Essa gota é, então, impulsionada através do arco elétrico para a poça de fusão pelo correto controle de corrente. $O$ pulso pode ser considerado de forma retangular, com aumentos e diminuições sucessivas da corrente de soldagem. Os parâmetros inerentes a uma curva retangular pulsada são lb (corrente de base), Tb (tempo de corrente de base), Ip (corrente de pulso) e Tp (tempo de corrente de pulso). Desta forma, quando não há a necessidade de altas potências e, portanto, há uma diminuição do valor da corrente, o sistema é resfriado. Esta característica do MIG/MAG pulsado faz com que este processo seja ideal para soldagem em materiais menos espessos, com bom controle sobre as distorções [2-4].

Entretanto, a seleção correta de parâmetros para o pulso é uma das maiores dificuldades para utilização do processo MAG pulsado. Para cada combinação de metal base, gás de proteção-tipo-diâmetro do eletrodo se tem um conjunto de parâmetros para obtenção de cordões de solda com as características desejadas [3,4].

O processo MIG/MAG Polaridade Variável vem crescendo em utilização em função de algumas características particulares, por exemplo, na soldagem de revestimento com aços inoxidáveis produz cordões de solda de alta qualidade e bom aspecto visual, mediante a seleção e ajustes adequados dos parâmetros da curva de corrente. Nos processos de soldagem ao arco elétrico a junta é submetida a ciclos de aquecimento e resfriamento gerando distorções que dificultam o projeto e a execução.

A utilização do processo de soldagem MIG/MAG Polaridade Variável (MIG/MAG PV) ainda é um desafio. A dificuldade operacional desse processo está no ajuste dos seis parâmetros da curva de corrente (Ip, Tp, In, Tn, Ib, Tb), sem considerar os parâmetros inerentes do processo de soldagem, que conduzam à obtenção de cordões de solda para revestimento em um nível otimizado de qualidade, sendo isto feito normalmente por tentativa e erro. Apesar das vantagens, os efeitos dos parâmetros negativos da curva de corrente sobre a distorção angular ainda não estão plenamente compreendidos. Alguns estudos têm sido publicados na literatura a respeito dos parâmetros com relação ao efeito sobre a geometria do cordão de solda e diluição [1,5].

Quando se trata de uma fonte de corrente, uma importante consideração a fazer é o sentido da corrente aplicada. No processo de soldagem MIG/MAG Convencional há significativa diferença entre as polaridades (CCEP: corrente contínua eletrodo positivo e CCEN: corrente contínua eletrodo negativo).

Ao trabalhar com corrente negativa (CCEN) há modificação na distribuição de energias entre o eletrodo e a peça. A Figura 1 mostra esquematicamente que com uma corrente positiva (CCEP) o calor concentra-se majoritariamente na peça e com corrente negativa (CCEN), no eletrodo, essa distribuição é cerca de $70 \%$ e $30 \%$ alternadamente para ambos os casos [6].

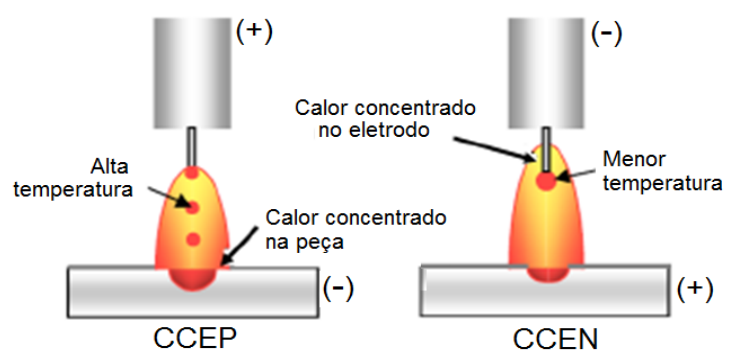

Figura 1. Comportamento do arco em CCEP e CCEN [[adaptado de [6]].

Nota-se na Figura 1, quando a polaridade do eletrodo é negativa (CCEN) a penetração é menor, outro fator positivo além da menor temperatura da peça é a maior taxa de fusão do arame - comparado ao CCEP. Contudo, o arco elétrico é muito instável nesse caso porque o modo de transferência predominante é o globular, como explica Talkington [7].

A polaridade variável (PV) difere da corrente alternada (CA) na peculiaridade dessa ser uma forma de onda senoidal onde a fração positiva é igual à negativa, enquanto a outra pode conter diferentes intensidades e tempos para cada uma das polaridades. A forma da curva de corrente MIG/MAG Polaridade Variável adotada tem, portanto, formato apresentado na Figura 2.

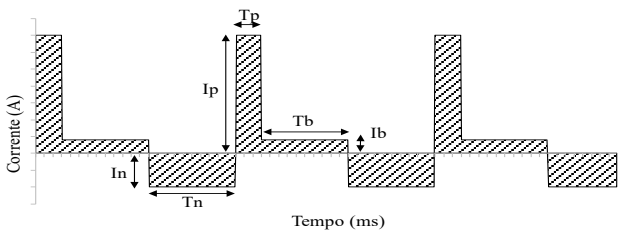

Figura 2. Curva de corrente MIG/MAG Polaridade Variável [fonte autor]. 
Os parâmetros inerentes da curva de polaridade variável (Figura 2) são: Ip: corrente de pulso positivo; Tp: tempo de pulso positivo; In: corrente de pulso negativa; Tn: tempo da corrente negativa; lb: corrente de base; Tb: tempo de base; T: período $(=\mathrm{Tp}+\mathrm{Tb}+\mathrm{Tn})$.

Para obter a curva de polaridade variável a partir da curva retangular pulsada é necessário adicionar dois novos parâmetros: In (corrente de pulso negativa) e Tn (tempo de corrente negativa). Os dois contribuem no processo de soldagem com suas particularidades.

O aumento da corrente de pulso negativa (In) aumenta a taxa de fusão do eletrodo, mas deve ser controlada em módulo para permitir a diminuição da temperatura da peça. Também, auxilia o fenômeno UGPP (uma gota por período de pulso) pois maior energia no eletrodo significa maior volume por unidade de tempo de eletrodo fundido e em consequência a gota formada será maior, para ser destacada e direcionada precisará de maior impulso.

O tempo da corrente negativa (Tn) é necessário ajustar para favorecer o resfriamento da peça e obter a penetração desejada quando usado o eletrodo negativo, mas no ajuste deve considerar-se a possibilidade da instabilidade no arco elétrico.

Distorções em estruturas soldadas são oriundas das expansões e contrações não lineares entre o cordão de solda e o metal base da junta. Podem ser relacionadas às distorções, problemas na montagem da estrutura, aparência e redução na resistência mecânica que originam atrasos e gastos adicionais com o alinhamento. Há um crescente esforço de engenheiros e pesquisadores para estabelecer técnicas de análise que facilitem o entendimento, controle e até a redução desse fenômeno.

As distorções, também designadas imperfeições geométricas, são alterações de forma e dimensão que ocorrem em componentes submetidos a determinados procedimentos de fabricação. No processo de soldagem as distorções são resultantes da aplicação não uniforme de calor. O gradiente de temperatura propicia as tensões térmicas, devido aos fenômenos de expansão térmica e contração que fiquem restringidas pelas áreas pouco aquecidas e que consequentemente aconteçam deformações plásticas [8,9]. Entre os fatores que influenciam as distorções pode-se mencionar: a magnitude da distorção angular dependerá da largura e profundidade da zona de fusão relativa à espessura da chapa, do tipo de junta, da sequência e número de passes, propriedades termomecânicas do material, presença de dispositivos restritivos e parâmetros relativos ao processo de soldagem, como por exemplo a energia de soldagem utilizada e a distribuição da energia do arco elétrico [10].

As tensões residuais induzidas no metal base devido às tensões térmicas presentes no fim do processo de soldagem podem ser da ordem do limite de escoamento do material. Essas, somadas a uma distribuição não-uniforme de altas temperaturas ao longo do volume, geram variações volumétricas e deformações plásticas.

Além das tensões residuais, e toda gama de fatores que podem ocasioná-las, uma variável importante que pode interferir no fenômeno da distorção é o grau de restrição ao movimento imposto à junta. Restrições mecânicas (gabaritos; dispositivos de fixação) dificultam as variações volumétricas por expansões e contrações térmicas.

A Figura 3 mostra que para uma determinada condição de soldagem, as tensões residuais, grau de restrição e distorção estão relacionadas da seguinte forma: que quanto menor o grau de restrição, menor será a tensão residual e maior será a distorção. Da mesma forma, quanto maior o grau de restrição, menor será a distorção e maior será a tensão residual. Altas tensões residuais diminuem a resistência à fadiga do material e aumentam a probabilidade de ocorrência de trincas e fraturas [11].

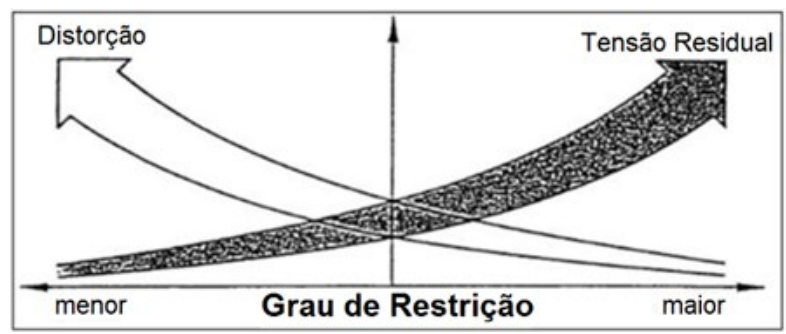

Figura 3. Relação Distorção x Tensão residual conforme grau de restrição [adaptado de [11]].

As distorções são comumente classificadas em seis categorias: contração longitudinal, contração transversal, distorção angular, distorção rotacional da peça em seu plano, distorção de flambagem e distorção de flexão (flexão longitudinal), ilustradas na Figura 4 [9]. As imperfeições encontradas frequentemente na construção naval e offshore são a distorção de flambagem e a distorção angular [12]. Entre os efeitos gerados pelas distorções pode-se mencionar o desalinhamento de componentes estruturais, grande quantidade de retrabalho para correção das imperfeições, aumento de custos, redução de eficiência de produção, imprecisão do produto final e detrimento de resistência estrutural [13]. 


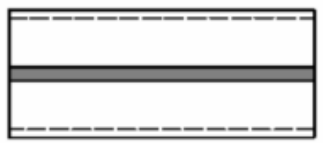

Contração

Transversal

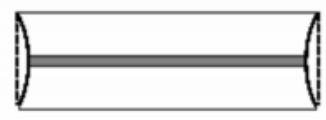

Contração

Longitudinal

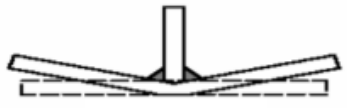

Distorção

Angular

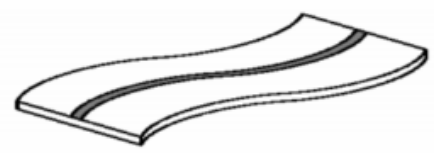

Distorção de

Flambagem

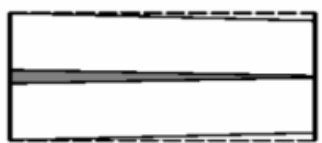

Distorção

Rotacional

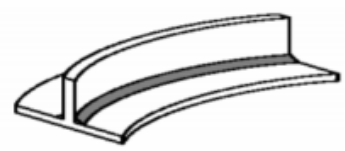

Distorção de Flexão

(Flexão Longitudinal)

Figura 4. Tipos de distorção na soldagem [adaptado de [9]].

No contexto das estruturas soldadas, as tensões residuais ficam restritas à vizinhança de uma solda e diminuem rapidamente em direções transversais ao cordão de solda. O perfil de tensões na direção transversal ao cordão de solda é dependente do grau de restrição ao movimento transversal e resultará em tensões de tração para regiões centrais à junta e tensões de compressão em suas extremidades, podendo ser somente de tração para situações em que as expansões e contrações sejam restringidas, representado pela curva na Figura 5.

A disposição irregular da zona plástica em relação à linha neutra de peça é a principal razão da distorção angular. A distorção angular ocorre quando a contração transversal não é uniforme ao longo da espessura da junta e pode ocorrer tanto em soldagem de juntas a topo como em juntas de filete, como ilustra a Figura 6. Na distorção angular (Figura 6), a distorção é transversal ao cordão de solda e fora do plano da junta. Segundo a AWS [14], a distorção angular ocorre quando as contrações transversais são não homogêneas na direção da espessura da junta.

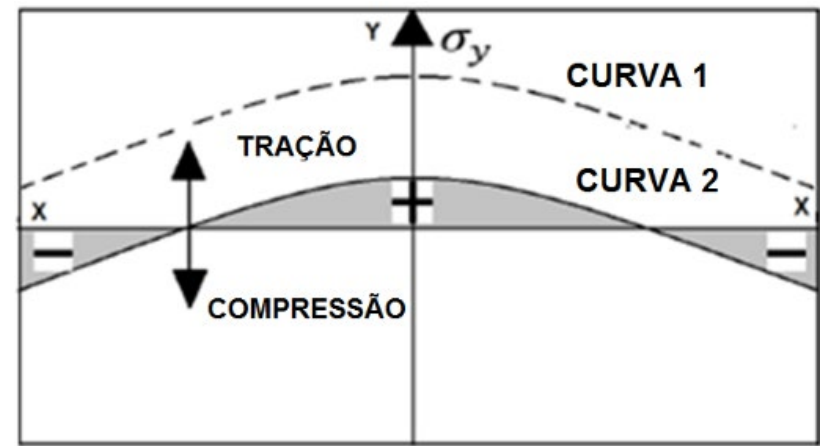

Figura 5. Tensão residual transversal ao cordão de solda: Curva 1: Sem restrição, Curva 2: Com restrição ao movimento de contração transversal [[adaptado de [14]].
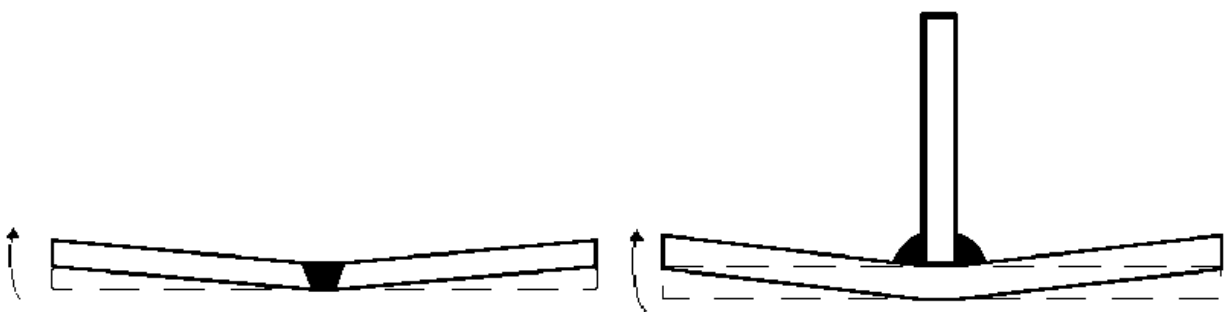

Figura 6. Distorção angular em juntas de topo e filete. Fonte Autor.

A metodologia de superfície de resposta (MSR) é, atualmente, o mais popular conjunto de técnicas para otimização, devido a sua completa teoria, eficiência e simplicidade $[15,16]$. A MSR consiste de um grupo de métodos matemáticos e estatísticos, que podem ser utilizados para definir as relações entre a resposta e as variáveis independentes. A MSR define o efeito de variáveis independentes, principal e/ou interações, sobre a variável dependente ou resposta do processo. Além de avaliar os 
efeitos das variáveis independentes, mediante a aplicação desta metodologia experimental é possível gerar um modelo matemático. A perspectiva gráfica do modelo matemático conduz ao nome de metodologia de superfície de resposta [16].

O projeto de experimentos é amplamente aplicado em todas as áreas do conhecimento, e possui como objetivo: planejar, executar e analisar o experimento, mediante uma metodologia científica e amparada por conceitos estatísticos. Esta metodologia é utilizada para otimizar um sistema ou processo, e é composta por etapas, iniciando por identificar o problema e quais são as características importantes desse processo.

O projeto Box- Behnken para três fatores requer apenas 12 ensaios, mais réplicas no ponto central. Em geral, o número de pontos experimentais é dado por $2 \mathrm{k}(\mathrm{k}-1)+\mathrm{C}_{0}$ (onde $\mathrm{k}$ é o número de fatores e $\mathrm{C}_{0}$ o número de réplicas do ponto central). Além disso, cada fator é estudado em apenas três níveis, um recurso importante em algumas situações experimentais [17].

Uma vez escolhido o projeto de experimento, a equação do modelo é definida e os coeficientes da equação do modelo são previstos. Na maioria dos problemas em Superfície de Resposta, a forma do relacionamento entre as variáveis dependentes e independentes é desconhecida. Assim, o primeiro passo é encontrar uma aproximação para o verdadeiro relacionamento entre a variável resposta $(y)$ e as variáveis independentes (fatores). Geralmente, utiliza-se uma equação de regressão polinomial de baixo grau em alguma região das variáveis independentes. Por exemplo, o modelo de regressão polinomial de segunda ordem é dado por [17]:

$y=\beta_{0}+\sum_{i=1}^{k} \beta_{i} x_{i}+\sum_{i=1}^{k} \beta_{i i} x_{i i}^{2}+\sum_{i=1}^{k-1} \sum_{j>i}^{k} \beta_{i j} x_{i} x_{j}+\varepsilon$

onde $B_{0}, B i$, Bii e $B_{i j}$ são os coeficientes do polinômio de regressão, linear, os coeficientes quadráticos e de interação, respectivamente, e $x_{i}$ e $x_{j}$ são as variáveis independentes, $\varepsilon$ é o termo de erro. Os coeficientes podem ser estimados eficientemente se for usado um projeto experimental adequado à coleta de dados.

O objetivo deste trabalho é avaliar o efeito da corrente negativa, do tempo da corrente negativa e do tempo da corrente de base positiva no processo de soldagem MAG Polaridade Variável, em particular para aplicações de revestimento, em relação à distorção angular da junta soldada, utilizando aço ao carbono como metal base e aço inoxidável como metal de adição.

\section{Materiais e Métodos}

A curva de corrente para o processo de soldagem MIG/MAG Polaridade Variável apresenta seis parâmetros independentes, neste experimento foram mantidos três ( $T p, I p, l b)$ constantes e os outros três ( $T b, T n$, In) foram variados em três níveis cada. Com o objetivo de entender o comportamento da polaridade negativa foram variados o tempo de corrente negativa ( $\mathrm{Tn}$ ) entre 5, 10 e 15 ms, e a corrente negativa (In) entre -150, -100 e -50 A. O tempo de corrente de base positiva (Tb) foi variado entre 5, 10 e 15 ms. Visando atingir a estabilidade do arco elétrico, a velocidade de alimentação do arame foi ajustada entre os experimentos com objetivo de manter a tensão elétrica de soldagem aproximadamente em $22 \mathrm{~V}$, e os parâmetros de pulso (positivo) empregados no experimento foram constantes: tempo de pulso positivo (Tp) de 3,0 ms e intensidade da corrente de pulso (Ip) de 350 A. Por fim, para a não extinção do arco elétrico, a intensidade da corrente de base (Ib) foi mantida constante em 40 A, conforme a Tabela 1.

O projeto de experimentos Box-Behnken e a MSR foram usados para estudar os efeitos de três variáveis independentes sobre as respostas e determinar a condição ótima que produza um cordão de solda de qualidade aceitável e mínima distorção angular $[16,18,19]$.

Na MSR há vários tipos de projeto de experimentos que podem ser usados, neste trabalho optou-se por aplicar o projeto Box-Behnken por requerer somente 15 ensaios para três parâmetros, e é aquele que necessita o menor número de experimentos comparado a outros. O projeto Box-Behnken, com base em três níveis fatoriais incompletos, tem a propriedade de rotacionalidade e o modelo de regressão polinomial pode ser de primeira ou de segunda ordem [17-19].

Os parâmetros inerentes do processo de soldagem como o tipo e vazão do gás de proteção, DBCP, velocidade de soldagem entre outros, foram mantidos constantes conforme a Tabela 2.

Os cordões de solda foram realizados sobre a superfície livre (bead-on-plate) e posição plana (1G), em chapas de aço SAE 1020 de 300x300x6,35 mm e aço inoxidável como metal de adição. O eletrodo utilizado no experimento foi o ER308LSi (aço inoxidável) de $1,2 \mathrm{~mm}$ de diâmetro. A vazão do gás de proteção $\left(\mathrm{Ar}+2 \% \mathrm{O}_{2}\right)$ foi mantida constante em $15 \mathrm{l} / \mathrm{min}$.

O experimento foi efetuado no Laboratório de Soldagem \& Técnicas Conexas da UFRGS. Os equipamentos utilizados foram: Tartílope V4 para movimentação da tocha, fonte de soldagem Multiprocessos DIGIPlus A7 450, sistema de aquisição portátil SAP 4.01 (IMC Soldagem), onde foram coletadas as informações de corrente e tensão dos experimentos, com uma taxa de aquisição de 5000 valores/s.

Na Tabela 3, apresenta-se a sequência aleatorizada do projeto de experimentos Box-Behnken para a soldagem dos corpos de prova de acordo com a combinação dos níveis dos fatores controláveis.

Tabela 1. Parâmetros da Curva de Corrente do Processo MIG/MAG Polaridade Variável. 


\begin{tabular}{|c|c|c|c|c|}
\hline \multirow{2}{*}{ Parâmetros } & \multicolumn{4}{|c|}{ Nível } \\
\hline & & Baixo & Médio & Alto \\
\hline Descrição & Símbolo & $(-1)$ & $(0)$ & $(+1)$ \\
\hline Tempo de corrente de base positiva (ms) & $\mathrm{Tb}$ & 5 & 10 & 15 \\
\hline Tempo de corrente negativa (ms) & $\mathrm{Tn}$ & 5 & 10 & 15 \\
\hline Corrente negativa $(A)$ & $\ln$ & -150 & -100 & -50 \\
\hline Corrente de pulso (A) & Ip & & Constante $=350$ & \\
\hline Tempo de pulso positivo (ms) & $\mathrm{Tp}$ & & Constante $=3,0$ & \\
\hline Corrente de base $(A)$ & $\mathrm{lb}$ & & Constante $=40$ & \\
\hline
\end{tabular}

Tabela 2. Parâmetros do Processo de Soldagem.

\begin{tabular}{cc}
\hline Parâmetros do Processo & Valores Constantes \\
Velocidade de Soldagem $(\mathrm{Vs})(\mathrm{cm} / \mathrm{min})$ & 25 \\
Ângulo de deslocamento da tocha $($ empurrando $)\left({ }^{\circ}\right)$ & -10 \\
Distância bico de contato peça $(\mathrm{DBCP})(\mathrm{mm})$ & 18 \\
Tensão de Soldagem $(\mathrm{V})$ & 22 \\
Vazão gás de proteção $(\mathrm{I} / \mathrm{min})$ & 15 \\
\hline
\end{tabular}

Os instrumentos para a medição da altura foram três relógios comparadores analógicos com capacidade de medição de $10 \mathrm{~mm}$ e resolução de $0,01 \mathrm{~mm}$, e para medição da distância um paquímetro digital com capacidade nominal de medição de $200 \mathrm{~mm}$ e resolução de $0,01 \mathrm{~mm}$.

Para a obtenção dos valores de distorção angular foram utilizados três relógios comparadores, (um no início, outro no meio e o terceiro no fim) na medição da altura "H - mm" (deslocamento vertical) da chapa e a distância "D - mm" da margem do cordão de solda ao ponto onde foi colocada a ponta de contato do relógio comparador. A restrição de um dos lados da chapa foi feita com três dispositivos de fixação dispostos ao longo da borda da chapa a soldar (Figura 7a, b, Figura 8). Os dados utilizados para a obtenção da distorção angular correspondem ao valor central da chapa, isto é, a $150 \mathrm{~mm}$ da borda da chapa, ao início do cordão de solda.

Após a soldagem foi disponibilizado um tempo de 15 minutos para o resfriamento e a estabilização dos ponteiros dos relógios que medem o deslocamento vertical no respectivo ponto. Logo, com um paquímetro digital foi medida a distância até a margem do cordão de solda, sendo possível, por semelhança de triângulos, obter em radianos a distorção angular, na posição média para cada combinação de parâmetros de cada ensaio.

As macrografias foram obtidas através da seção transversal de cada um dos cordões de solda, os quais foram lixados e em seguida atacados com Nital $2 \%$.

Tabela 3. Sequência (aleatorizada) e combinação dos parâmetros segundo o projeto de experimentos Box-Behnken para a soldagem dos corpos de prova, e a resposta.

\begin{tabular}{|c|c|c|c|c|}
\hline \multirow{2}{*}{$\begin{array}{l}\text { Sequência } \\
\text { dos Ensaios }\end{array}$} & \multicolumn{3}{|c|}{ Fatores Controláveis } & \multirow{2}{*}{$\begin{array}{c}\text { Resposta } \\
\text { Distorção Angular (rad) }\end{array}$} \\
\hline & Tb (ms) & Tn (ms) & $\ln (\mathrm{A})$ & \\
\hline \#1 (ponto central) & 10 & 10 & -100 & 0,037672 \\
\hline$\# 2$ & 15 & 15 & -100 & 0,030419 \\
\hline$\# 3$ & 15 & 5 & -100 & 0,037760 \\
\hline$\# 4$ & 15 & 10 & -150 & 0,036890 \\
\hline$\# 5$ & 10 & 15 & -150 & 0,042988 \\
\hline$\# 6$ & 15 & 10 & -50 & 0,035842 \\
\hline$\# 7$ & 10 & 5 & -50 & 0,038267 \\
\hline$\# 8$ & 5 & 10 & -50 & 0,034624 \\
\hline$\# 9$ & 5 & 15 & -100 & 0,035928 \\
\hline$\# 10$ & 5 & 5 & -100 & 0,038771 \\
\hline \#11 (ponto central) & 10 & 10 & -100 & 0,037554 \\
\hline$\# 12$ & 5 & 10 & -150 & 0,034772 \\
\hline \#13 (ponto central) & 10 & 10 & -100 & 0,036509 \\
\hline$\# 14$ & 10 & 5 & -150 & 0,047284 \\
\hline$\# 15$ & 10 & 15 & -50 & 0,028625 \\
\hline
\end{tabular}

Nota: O símbolo \# identifica a sequência aleatorizada de realização dos ensaios. 


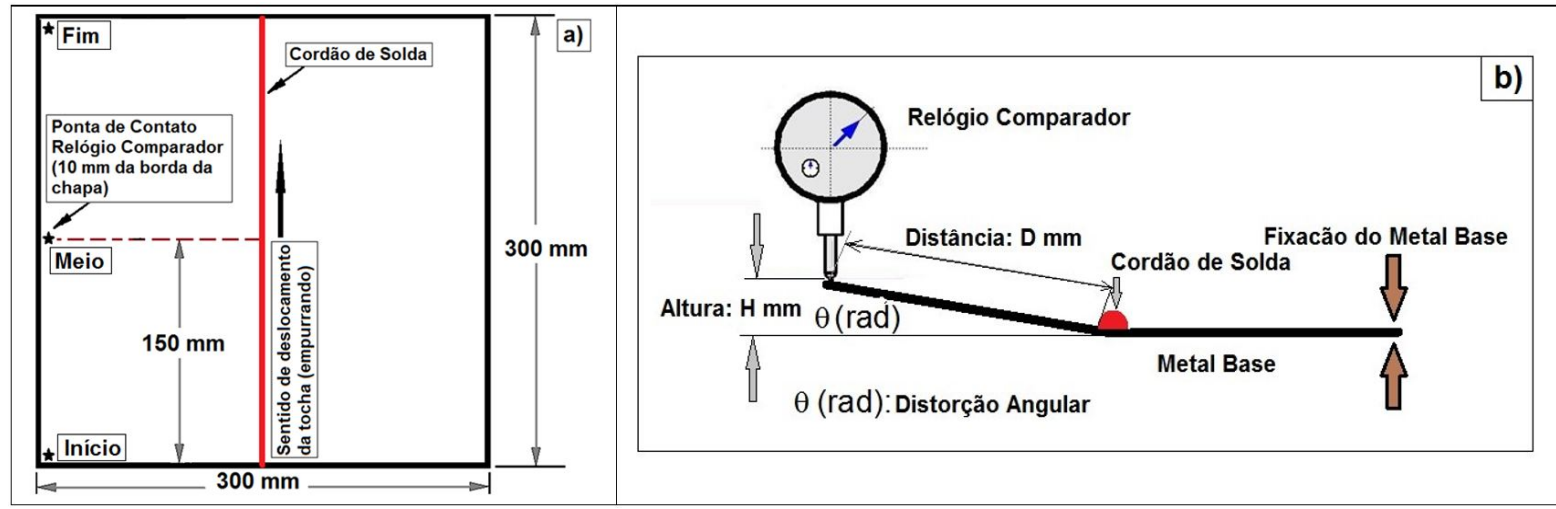

Figura 7. (a) Esquema mostrando as dimensões da chapa soldada; (b) medição da altura e distância para determinação da distorção angular. Nota: O símbolo * identifica o local onde foi colocada a ponta de contato do relógio comparador.

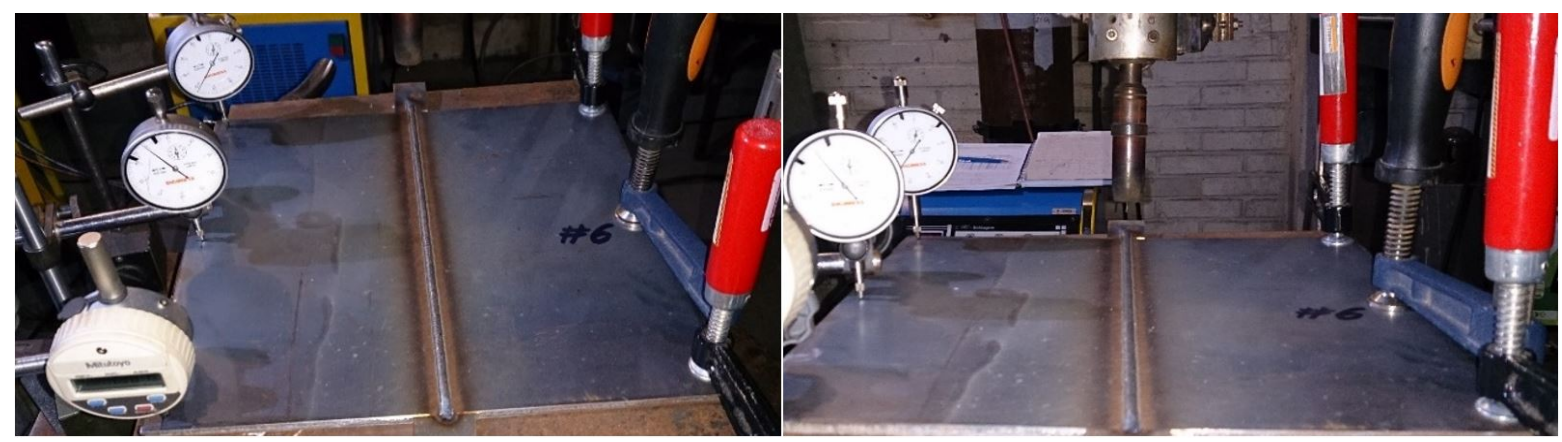

Figura 8. Corpo de prova do ensaio \#6, aspecto do cordão de solda, dispositivos de fixação do corpo de prova, relógios comparadores posicionados. Ensaio \#6: $\mathrm{Tb}=15 \mathrm{~ms} ; \mathrm{Tn}=10 \mathrm{~ms} ; \mathrm{ln}=-50 \mathrm{~A}$.

\section{Resultados e Discussão}

Realizadas as medições da altura e distância das 15 chapas soldadas pelo processo MAG PV utilizando o gás de proteção $\mathrm{Ar}+2 \% \mathrm{O}_{2}$ para cada combinação de parâmetros foram obtidos o valor de distorção angular (vide Figura 7) em radianos, conforme a Tabela 3.

Nas Figuras 9a, b podem ser observados os oscilogramas de tensão e corrente de soldagem em função do tempo para o ensaio \#1 com os seguintes parâmetros Tb $=10 \mathrm{~ms}, \mathrm{Tn}=10 \mathrm{~ms}$, In = -100 A.

Conforme a Figura 9a, para o ensaio\#1, a oscilação apresentada no formato do pulso de tensão o valor foi aproximadamente de $30 \mathrm{~V}$ e quando se inicia a transição do pulso passa para aproximadamente $20 \mathrm{~V}$. A oscilação da tensão do arco elétrico ocorreu nessa região para todas as situações. O oscilograma de corrente de soldagem se manteve estável para os 15 ensaios da matriz experimental do projeto de experimentos Box-Behnken (vide Tabela 3).

Nas Figura 10 e Figura 11a, b podem ser observados os oscilogramas de tensão e corrente de soldagem em função do tempo para os ensaios \#5 e \#15, respectivamente.

As Figuras 12a, b, Figuras 13a, b, Figuras 14a, b, mostram o aspecto superficial do cordão de solda e macrografia da seção transversal do cordão de solda para os ensaios \#1, \#5 e \#15, respectivamente. Nessas figuras observa-se o efeito da alteração dos parâmetros deste estudo sobre o aspecto e geometria do cordão de solda. 


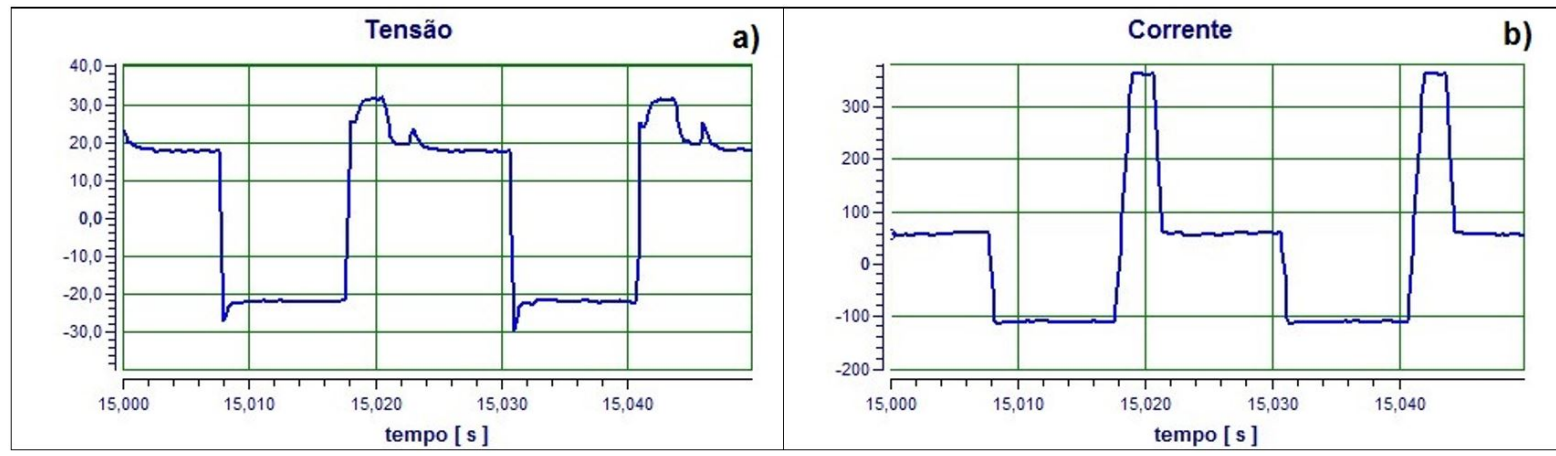

Figura 9. Ensaio \#1: $\mathrm{Tb}=10 \mathrm{~ms}, \mathrm{Tn}=10 \mathrm{~ms}, \mathrm{In}=-100 \mathrm{~A}$. (a) Oscilograma de tensão instantânea do arco em $\mathrm{V}$; (b) Oscilograma de corrente instantânea de soldagem em A.

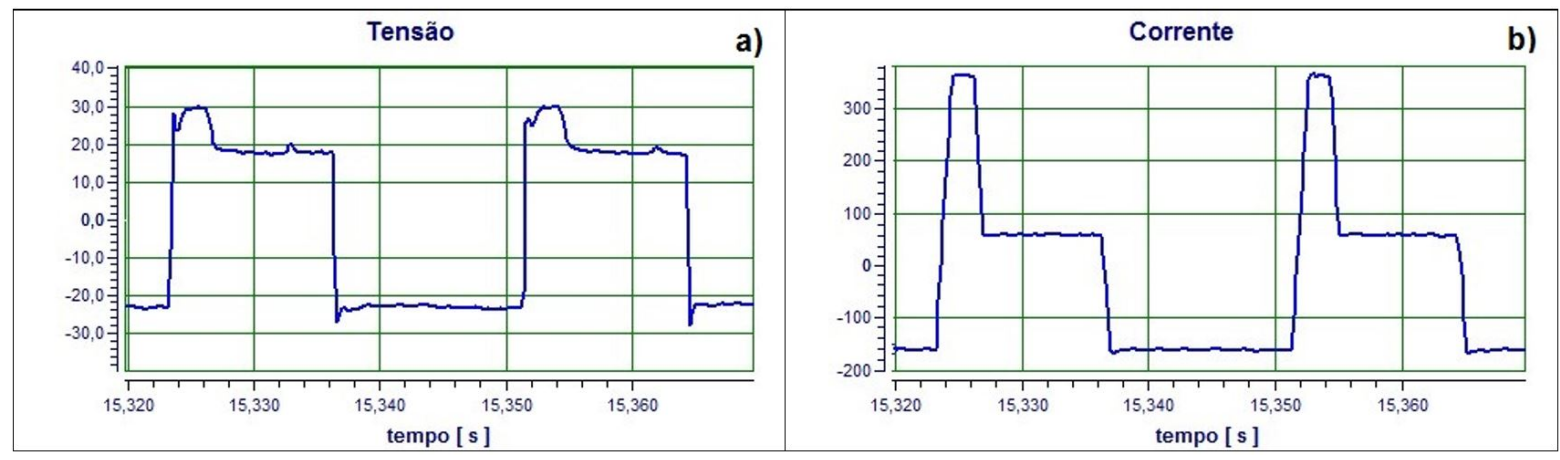

Figura 10. Ensaio \#5: $\mathrm{Tb}=10 \mathrm{~ms}, \mathrm{Tn}=15 \mathrm{~ms}$, In = -150 A. (a) Oscilograma de tensão instantânea do arco em $\mathrm{V}$; (b) Oscilograma de corrente instantânea de soldagem em A.

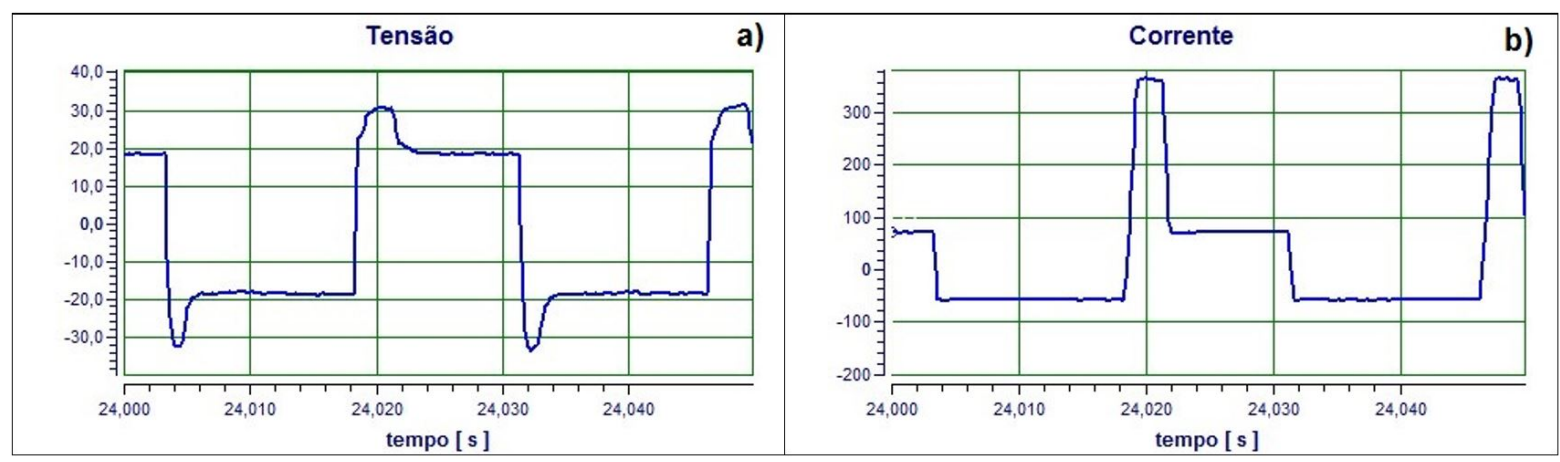

Figura 11. Ensaio \#15: Tb = $10 \mathrm{~ms} ; \mathrm{Tn}=15 \mathrm{~ms} ; \mathrm{In}=-50 \mathrm{~A}$. (a) Oscilograma de tensão instantânea do arco em V. (b) Oscilograma de corrente instantânea de soldagem em $A$.

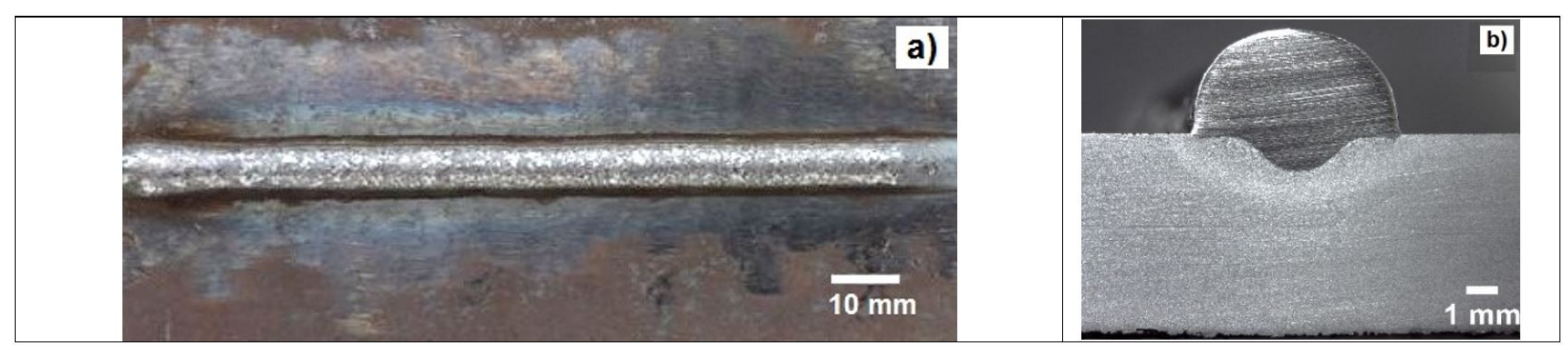

Figura 12. (a) Aspecto superficial do cordão de solda, (b) macrografia da seção transversal do cordão de solda para o ensaio \#1: Tb = 10 ms, $\mathrm{Tn}=10 \mathrm{~ms}, \ln =-100 \mathrm{~A}$. 


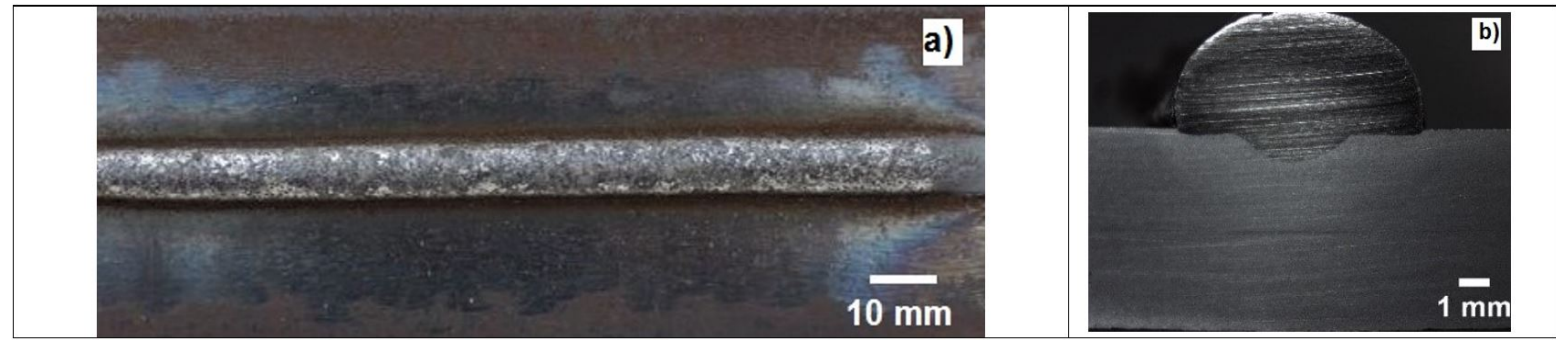

Figura 13. (a) Aspecto superficial do cordão de solda; (b) macrografia da seção transversal do cordão de solda para o ensaio \#5: $\mathrm{Tb}=10 \mathrm{~ms}$, $\mathrm{Tn}=15 \mathrm{~ms}, \ln =-150 \mathrm{~A}$.

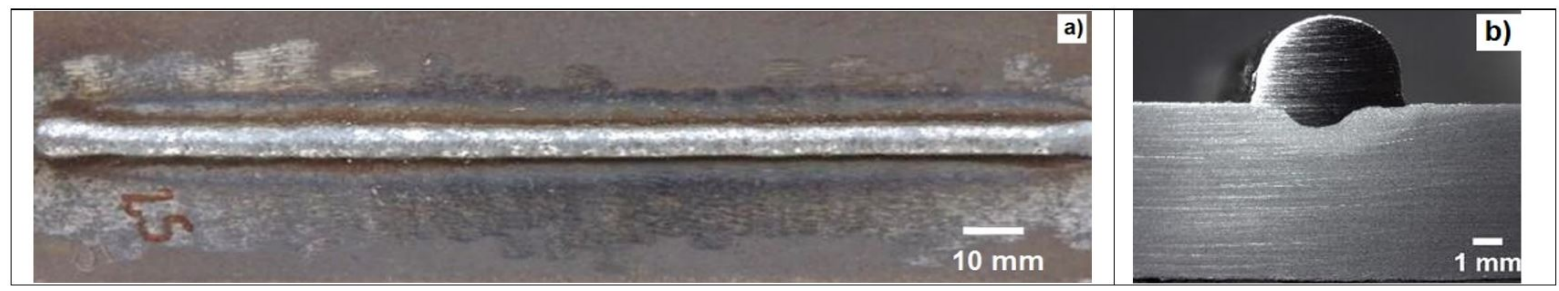

Figura 14. (a) Aspecto superficial do cordão de solda; (b) macrografia da seção transversal do cordão de solda para o ensaio \#15: Tb = 10 ms; $\mathrm{Tn}=15 \mathrm{~ms} ; \mathrm{ln}=-50 \mathrm{~A}$.

Devido à complexidade do formato da onda de polaridade variável, o entendimento direto da alteração dos parâmetros Tb, Tn, In da curva na distorção angular da peça não é simples de entender o efeito dos parâmetros. Para tanto, a análise estatística baseada em projetos de experimentos se torna uma ferramenta valiosa para a exploração e entendimento dos fenômenos envolvidos.

A Tabela 3 mostra o projeto de experimentos Box-Behnken com os três parâmetros controláveis de processo e os valores da distorção angular para cada ensaio - combinação dos valores de cada parâmetro - o tratamento dos dados através das técnicas estatísticas.

Na Tabela 4 apresenta-se a Análise de Variância (ANOVA) para a distorção angular ( $\theta$ - rad) da junta soldada. O valor-p pode ser utilizado na determinação da significância dos fatores principais ou interações sobre a distorção angular. Esse valor é um indicador que quantifica a significância com relação à resposta. O termo valor-p é conhecido pela probabilidade de significância, caso apresente valores superior a 0,05 (5\%) pode-se rejeitar a hipótese nula (fator não é significativo) com 95\% de confiança. Mediante a ANOVA foi determinada que os parâmetros principais Tb, Tn e In têm forte efeito significativo na distorção angular para um nível de significância $\alpha=0,05$ (Valor-p < 0,05). Entretanto, as interações Tn*In e Tb*Tn apresentam moderado efeito significativo sobre a distorção angular para um nível de significância $0,05<\alpha \leq 0,10(0,05<$ Valor-p $\leq 0,10)$.

Na Tabela 4 a coluna da proporção que cada fator representa em relação ao total dos efeitos, mostrando assim uma grande parcela da influência dos efeitos para os fatores individuais, a contribuição do In sobre a distorção angular é de $28,67 \%$, Tn é de 28,18\% e Tb de 9,86\%. Entretanto, a contribuição das interações $T n *$ In representa um 2,60\% e Tb*Tn um 1,84\%.

Tabela 4. ANOVA dos fatores Tb, Tn e In sobre a distorção angular.

\begin{tabular}{ccccccc}
\hline Fator & SQ & GDL & MQ & Fcal & Valor-p & Proporção \% \\
Tb (ms) $L+Q$ & $\mathbf{0 , 0 0 0 0 2 7 0 4 6}$ & $\mathbf{2}$ & $\mathbf{0 , 0 0 0 0 1 3 5 2 3}$ & $\mathbf{3 2 , 9 9 5}$ & $\mathbf{0 , 0 2 9 4}$ & $\mathbf{9 , 8 6}$ \\
Tn (ms) L+Q & $\mathbf{0 , 0 0 0 0 7 7 3 3 3}$ & $\mathbf{2}$ & $\mathbf{0 , 0 0 0 0 3 8 6 6 6}$ & $\mathbf{9 4 , 3 4 2}$ & $\mathbf{0 , 0 1 0 5}$ & $\mathbf{2 8 , 1 8}$ \\
In (A) L+Q & $\mathbf{0 , 0 0 0 0 7 8 6 8 2}$ & $\mathbf{2}$ & $\mathbf{0 , 0 0 0 0 3 9 3 4 1}$ & $\mathbf{9 5 , 9 8 9}$ & $\mathbf{0 , 0 1 0 3}$ & $\mathbf{2 8 , 6 7}$ \\
Tb (L) por Tn (L) & 0,000005057 & 1 & 0,000005057 & 12,339 & 0,0724 & 1,84 \\
Tb (L) por In (L) & 0,000000203 & 1 & 0,000000203 & 0,494 & 0,5549 & 0,07 \\
Tn (L) por In (L) & 0,000007146 & 1 & 0,000007146 & 17,435 & 0,0528 & 2,60 \\
Falta de ajuste & 0,000075416 & 3 & 0,000025139 & 61,336 & 0,0161 \\
Erro & 0,000000820 & 2 & 0,000000410 & & & \\
Total SQ & 0,000274 & 14 & & & \\
\hline
\end{tabular}

Nota: SQ: soma dos quadrados; GDL: graus de liberdade; MQ: média dos quadrados; L: linear; Q: quadrático.

A Figura 15 relaciona os efeitos principais sobre a distorção angular, sendo importante considerar que o tempo de corrente negativa (Tn) afeta a distorção, quando varia de 5 a 15 ms ocorre uma redução da distorção angular de 0,040 para 0,035 rad. A corrente negativa (In) tem efeito significativo sobre a distorção angular, e para uma redução em valor absoluto da corrente, de -150 a -50 A, causa redução na distorção angular, semelhante ao Tn, de 0,040 para 0,035 rad. O efeito do tempo de base (Tb) sobre a distorção angular, de 5 ms a 10 ms há um aumento, e de 10 a 15 ms causa redução da distorção angular em 0,035 rad. 
Na Figura 16 se observa o efeito da interação dos fatores Tn e Tb para a distorção (rad), o menor valor da resposta se obtem para $\mathrm{Tn}=15 \mathrm{~ms}$ e Tb = $15 \mathrm{~ms}$. A Figura 17 mostra o efeito da interação dos fatores In e Tn para a distorção (rad), a maior distorção angular ( $\cong 0,047 \mathrm{rad}$ ) para $\mathrm{Tn}=5 \mathrm{~ms}$ e $\mathrm{In}=-150 \mathrm{~A}$. Quando a corrente negativa em valor absoluto for maior (150 A) e Tn $=5 \mathrm{~ms}$, afetam a corrente média (Ip, Tp e Ib, permanecem constantes), por consequência afetam a energia de soldagem

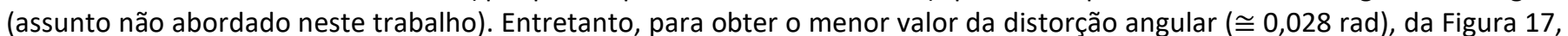
é necessário ajustar os parâmetros $\mathrm{Tn}=15 \mathrm{~ms}$ e In = -50 A.

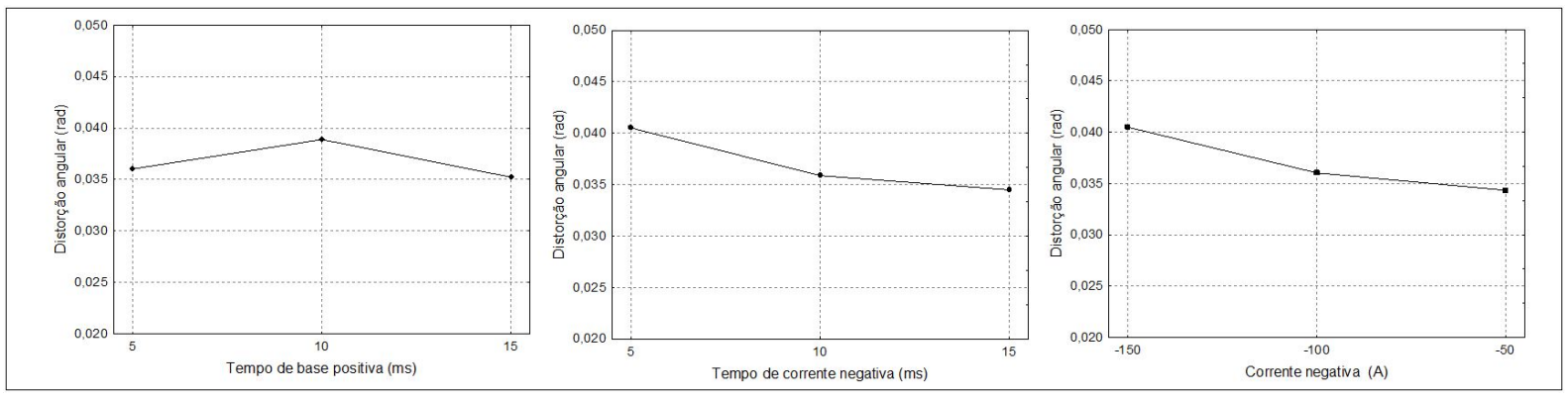

Figura 15. Gráfico dos efeitos dos parâmetros principais (Tb, Tn e In) para a distorção angular.

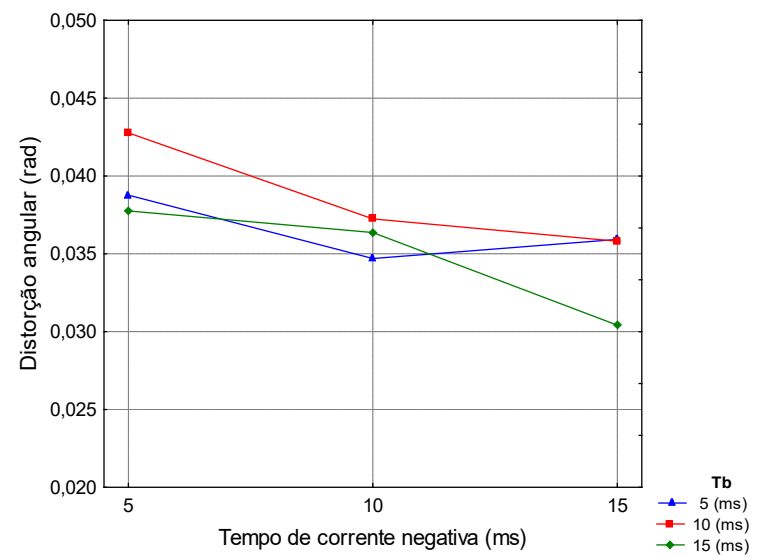

Figura 16. Gráfico da interação dos fatores para a distorção angular (rad) em relação a Tn e Tb.

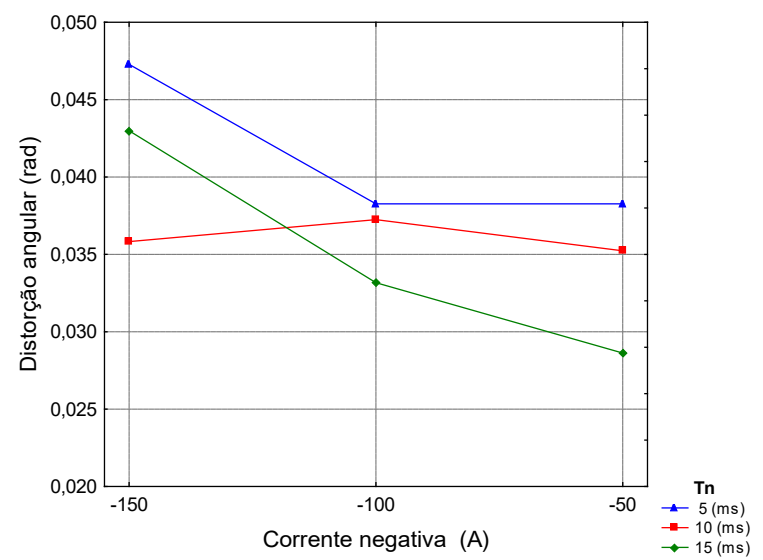

Figura 17. Gráfico da interação dos fatores para a distorção angular (rad) em relação a In e Tn.

\subsection{Modelagem e otimização de parâmetros de processo}

Mediante o modelo de regressão polinomial de segundo grau é possível determinar uma relação numérica entre a distorção angular ( $\theta$ - rad) e as variáveis independentes, que em geral é desconhecida. $O$ objetivo do uso da metodologia de superfície de resposta (MSR) é desenvolver um modelo matemático da superfície de resposta de segunda ordem com o melhor ajuste e encontrar o conjunto ótimo de parâmetros experimentais que produzam um valor máximo ou mínimo de resposta. Com base nos resultados obtidos a partir do projeto de experimentos Box-Behnken, um modelo de regressão de segunda ordem 
para a distorção angular (rad) foi desenvolvido em termos dos valores reais (não-codificado) dos fatores e interações avaliados, ver a Equação 2.

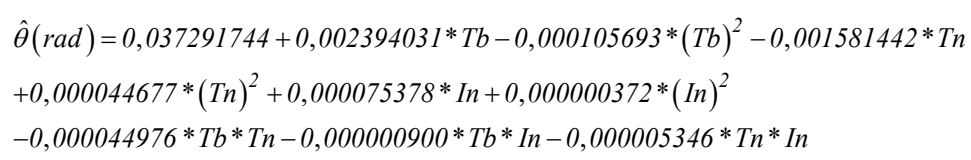

A Figura 18 mostra o gráfico da superfície de resposta do valor esperado da distorção angular em função da interação do tempo da corrente negativa ( $\mathrm{Tn}$ - ms) e corrente negativa (In - A) para Tb = $15 \mathrm{~ms}$, e a Figura 19 mostra o gráfico de contorno obtido a partir dessa superfície de resposta, mostrando o valor estimado da distorção angular em função da interação Tn * In para $\mathrm{Tb}=15 \mathrm{~ms}$.

A análise da Figura 18 revela que a distorção angular diminui com a diminuição da corrente em valor absoluto (de -150 a $-50 \mathrm{~A}$ ) e o aumento do tempo de corrente negativa (de 5 a $15 \mathrm{~ms}$ ), a região de menor valor de distorção $(<0,028$ rad) pode ser obtido quando $\mathrm{Tn}=15 \mathrm{~ms}, \mathrm{In}=-50 \mathrm{~A}$ e $\mathrm{Tb}=15 \mathrm{~ms}$.

A Figura 20 apresenta o contorno da superfície de resposta da distorção angular em função da interação Tn * In para $\mathrm{Tb}=5 \mathrm{~ms}$, observa-se que o valor da distorção estimado é menor que 0032 rad. Para um aumento do tempo de base de $5 \mathrm{~ms}$ para $\mathrm{Tb}=10 \mathrm{~ms}$, Figura 21, causa um aumento na distorção angular, e é possível observar a área maior da distorção angular (curva de 0,034 rad).

O menor valor de distorção angular estimado da junta, quando $\mathrm{Tn}=15 \mathrm{~ms}$, In = -50 A e Tb = 15 ms, pode ser pela menor energia de soldagem (calor transferido ao metal base). O formato da curva de corrente de polaridade variável é complexo, o entendimento e explicação da alteração dos parâmetros da curva no calor transferido para a peça, geometria do cordão de solda e estabilidade do arco requer de mais estudos. A análise dos parâmetros mediante a metodologia de projeto de experimentos e metodologia de superfície de resposta são ferramentas que ajudam a explorar e encontrar a relação entre resposta e variáveis independentes (parâmetros).

$\mathrm{Na}$ avaliação dos valores dos parâmetros Tb, Tn e In, percebe-se que o aumento de Tn e diminuição (em módulo) de In (parâmetros da polaridade negativa), favorece o resfriamento da peça. Isso causa uma menor distorção angular. Segundo Kim et al. [6], há maior aquecimento no eletrodo (aproximadamente 70\%) e menor energia é transferida ao metal base (aproximadamente 30\%). No processo MAG pulsado [4], durante a aplicação da corrente de base ocorre resfriamento da peça e quanto maior for o tempo de base $\mathrm{Tb}=15 \mathrm{~ms}$ menor distorção angular se obtém. A conclusão que se chega é que ele favorece também o resfriamento da peça, por estar sustentando uma corrente de soldagem positiva baixa suficiente para manter aceso o arco elétrico, responsável apenas pela manutenção do arco elétrico.

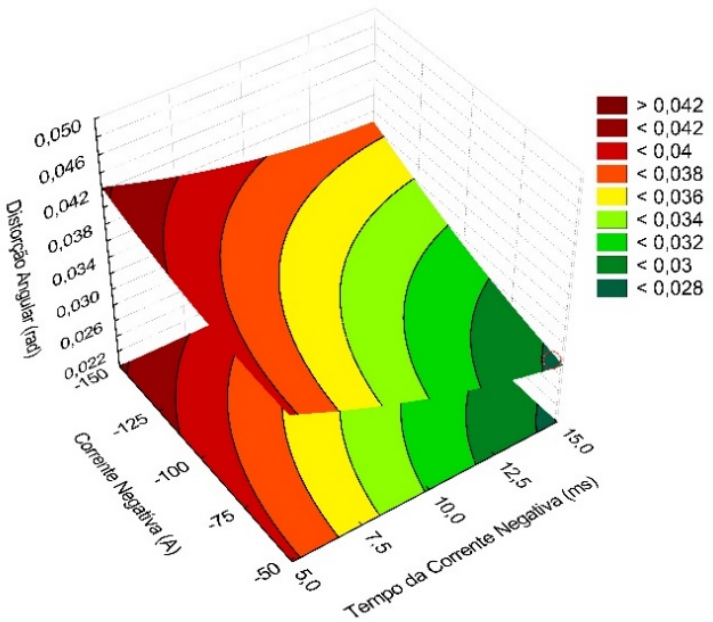

Figura 18. Superfície de resposta, mostrando o valor estimado da distorção angular em função da interação $\mathrm{Tn}$ * In para Tb $=15$ ms. 


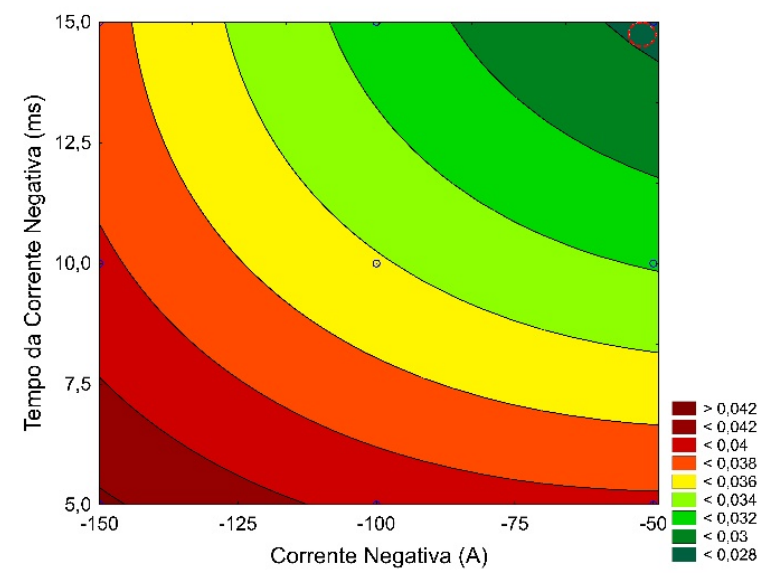

Figura 19. Contorno de superfície de resposta, mostrando o valor estimado da distorção angular em função da interação Tn *In para Tb = 15 ms.

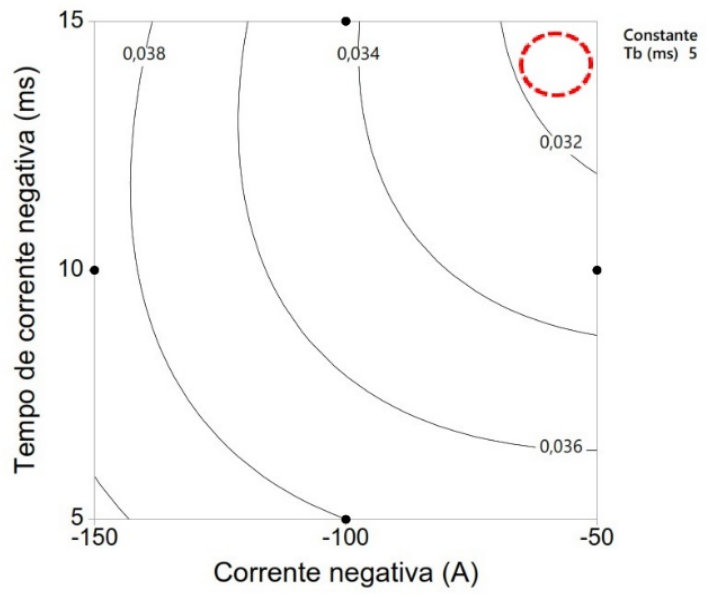

Figura 20. Contorno de superfície de resposta, mostrando o valor estimado da distorção angular em função da interação $\mathrm{Tn} * \ln$ para $\mathrm{Tb}=5 \mathrm{~ms}$.

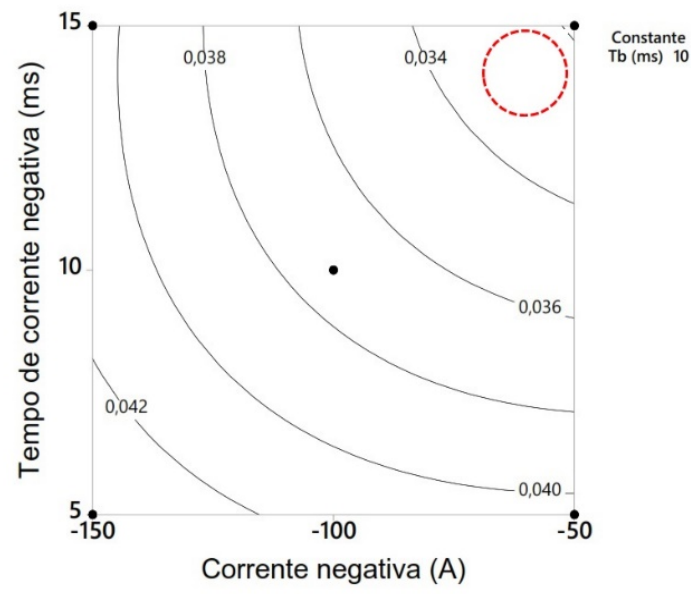

Figura 21. Contorno de superfície de resposta, mostrando o valor estimado da distorção angular em função da interação $\mathrm{Tn}$ *In para Tb = 10 ms .

\subsection{Validação do modelo matemático}

Validação do modelo matemático/estatístico da distorção angular em função dos parâmetros no intervalo avaliado. Para tanto foi definido o Erro (\%), como se mostra na Equação 3:

Erro $(\%)=\frac{\text { Valor observado }- \text { Valor estimado }}{\text { Valor estimado }} .100 \%$ 
O valor estimado da distorção angular pode ser obtido substituindo os valores dos parâmetros na faixa avaliada na equação de regressão (Equação 2). Com os mesmos valores de parâmetros ajustar (introduzir no ajuste dos parâmetros do processo) a fonte de soldagem e realizar o cordão de solda, logo medir a altura e a distância para obter o valor experimental (valor observado). Obtendo os valores observado e estimado da distorção angular pode ser determinado o erro \% segundo a Equação 3.

\subsection{Menor valor da distorção angular estimado}

A função desejabilidade (Desirability) é um método utilizado para determinar as melhores condições de ajuste de um processo, tornando possível a otimização simultânea de múltiplas respostas.

Ao contrário das variáveis independentes, a magnitude da resposta (ou das respostas) depende da combinação entre os níveis dos fatores e se constituem dos valores de propriedades medidas a partir da execução dos experimentos definidos por uma matriz experimental. Uma situação muito comum é a necessidade de otimizar várias respostas ao mesmo tempo.

A função desejabilidade, proposta por Derringer e Suich em 1980 [18], permite trabalhar com multirespostas, e baseia-se na transformação de cada resposta individual em uma escala adimensional de desejabilidades individuais $\left(d_{i}\right)$. A escala de desejabilidades individuais pode variar de 0 (para uma resposta inaceitável) a 1 (para a resposta desejada). Esta transformação torna possível combinar os resultados obtidos para as propriedades medidas em diferentes ordens de grandeza. Com as desejabilidades individuais, torna-se possível obter a desejabilidade global (D), definida como a média geométrica das desejabilidades individuais $\left(d_{i}\right), D=\sqrt[m]{d_{1} \cdot d_{2} \ldots d_{m}}$ (onde $m$ é o número de respostas avaliadas) e pode variar de 0 a 1.

Funções para o cálculo de desejabilidades individuais também podem ser estabelecidas para outras situações como o valor alvo ser um mínimo ou estiver localizado entre um valor mínimo e um valor máximo. A aplicação de função de desejabilidade na otimização de métodos analíticos traz inúmeras vantagens como eficiência, economia e objetividade na otimização de procedimentos com múltiplas respostas. As melhores condições das respostas são obtidas simultaneamente, minimizando-se, maximizando-se ou buscando-se valores nominais de especificações, dependendo da situação mais conveniente para o processo.

Foi determinada a função desejabilidade para a única resposta objetivo "menor valor de distorção" mediante o software Minitab ${ }^{\circledR}$. Desta forma, quanto mais próximo de 1 for o valor obtido, mais próximo estarão os valores ótimos relacionados a cada resposta individual. O ponto ótimo encontrado pela avaliação dos resultados experimentais foi caracterizado como um ponto que possui um valor de $D=1,0000$ para a desejabilidade mostrando que é possível obter, valor estimado, 0,0275 rad, para os valores de $\mathrm{Tb}=15 \mathrm{~ms}$, $\mathrm{Tn}=15 \mathrm{~ms}$ e $\mathrm{In}=-50 \mathrm{~A}$, e são apresentados na Figura 22 e na Tabela 5 . Na Tabela 6 são apresentados o valor observado $(0,0285 \mathrm{rad})$ e o valor estimado $(0,0275 \mathrm{rad})$. 0 erro obtido é $-3,54 \%$, o que significa que o valor da distorção angular obtido experimentalmente é ligeiramente maior ao estimado mediante a Equação 2 de regressão. Também, avaliando o gráfico de contorno da superfície de resposta (Figura 19) é possível definir a região de menor valor para a distorção angular (rad) em relação a $\mathrm{Tn}$ e $\mathrm{In}$, e valor constante de $\mathrm{Tb}=15 \mathrm{~ms}$.

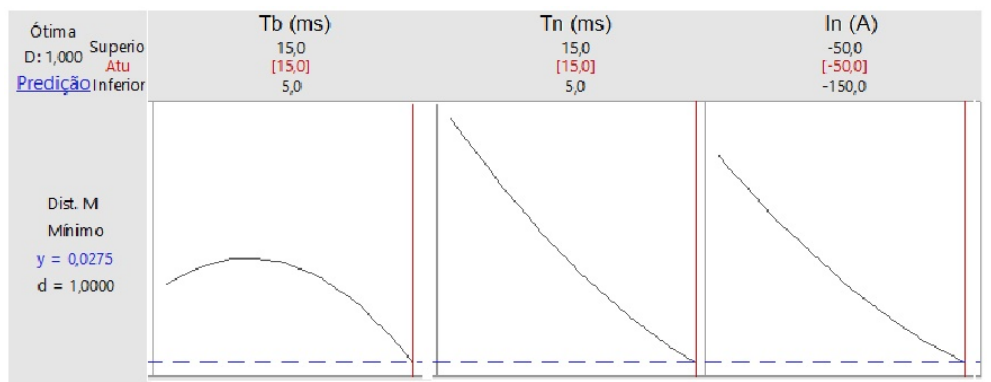

Figura 22. Valores dos parâmetros Tb, Tn e In para o valor objetivo: menor valor de distorção angular.

Tabela 5. Valores dos parâmetros de configuração.

\begin{tabular}{ccc} 
Descrição & Símbolo & Valor \\
Tempo de corrente de base positiva & Tb & $15 \mathrm{~ms}$ \\
Tempo de corrente negativa & $\mathrm{Tn}$ & $15 \mathrm{~ms}$ \\
Corrente negativa & $\mathrm{In}$ & $-50 \mathrm{~A}$ \\
\hline
\end{tabular}

Tabela 6. Menor Valor de Distorção Angular para os parâmetros avaliados.

\begin{tabular}{cc}
\hline Distorção Angular & $\boldsymbol{\theta}-$ rad \\
Valor Observado (Experimental) & 0,02848067 \\
Equação 2 - Valor Estimado & 0,02747777 \\
Equação 3 Erro (\%) & 3,65 \\
\hline
\end{tabular}




\subsection{Valor estimado da distorção angular para a menor diluição}

Os valores dos parâmetros (Tb, Tn e In) determinados por [1], para a mínima diluição da junta soldada de aço ao carbono e metal de adição de aço inoxidável, as mesmas condições foram usadas neste trabalho, portanto foi possível aplicar os parâmetros da Tabela 7. Na Tabela 8 são apresentados o valor observado (0,0300 rad) e o valor estimado (0,0275 rad), e o erro obtido é $-3,54 \%$, o que significa que o valor da distorção angular obtido experimentalmente é menor ao estimado mediante a Equação 2 de regressão para a distorção angular (rad).

Tabela 7. Valores dos parâmetros de configuração [1].

\begin{tabular}{ccc}
\hline Descrição & Símbolo & Valor \\
Tempo de corrente de base positiva & $\mathrm{Tb}$ & $11,5 \mathrm{~ms}$ \\
Tempo de corrente negativa & $\mathrm{Tn}$ & $15 \mathrm{~ms}$ \\
Corrente negativa & $\mathrm{In}$ & $-50 \mathrm{~A}$ \\
\hline
\end{tabular}

Tabela 8. Valor da Distorção Angular para a Menor Diluição.

\begin{tabular}{cc}
\hline Distorção Angular & $\boldsymbol{\theta}$ - rad \\
Valor Observado (Experimental) & 0,030005527 \\
Equação 2 - Valor Estimado & 0,031105409 \\
Equação 3 Erro (\%) & $-3,54$ \\
\hline
\end{tabular}

\section{Conclusões}

Com base no estudo realizado, dos parâmetros da curva de corrente do processo MAG Polaridade Variável, pode-se concluir que mediante a combinação adequada dos parâmetros dentro dos limites avaliados é possível obter a resposta desejada.

a) O projeto de experimentos Box-Behnken é adequado para a obtenção do modelo matemático/estatístico para estimar os valores da distorção angular, usando o processo MAG PV;

b) Na distorção angular, os parâmetros tempo de base (Tb) e tempo da corrente negativa (Tn) e corrente negativa (In) se mostraram fortemente significativos. As interações $\mathrm{Tb}^{*} \mathrm{Tn}$ e $\mathrm{Tn} * \mathrm{In}$ apresentam efeitos moderamente significativos sobre a distorção angular. Nota-se um comportamento complexo e que para obter o menor valor é necessário ajustar adequadamente os três parâmetros avaliados;

c) A metodologia de superfície de resposta é uma ferramenta muito importante na obtenção do conjunto de condições do processo quando há necessidade de estimar a resposta alvo ou objetivo, os gráficos de contornos podem determinar a região do ótimo;

d) Para o menor valor da distorção angular, a diferença (erro \%) entre os valores estimado e observado foi de 3,65\%;

e) Para o menor valor de diluição, a diferença (erro \%) entre os valores estimado e observado foi de $-3,54 \%$.

\section{Referências}

[1] Baumgaertner AJ. (2017). Análise dos parâmetros da polaridade negativa na curva de corrente de soldagem MIG/MAG polaridade variável aplicados à soldagem para revestimento [Dissertação de mestrado]. Porto Alegre: Universidade Federal do Rio Grande do Sul.

[2] American Welding Society - AWS. Welding handbook, welding processes: part 1. 9th ed., Vol. 2. Miami: American Welding Society; 2004.

[3] Gonzalez AR. Efeito da forma da onda sobre as características de fusão na soldagem MIG/MAG com corrente pulsada [Tese de doutorado]. Porto Alegre: Universidade Federal do Rio Grande do Sul; 1997.

[4] Amin M. Pulse current parameters for arc stability and controlled metal transfer. Arc Welding, Metal Construction, 1983;15(5), 272-278.

[5] Dutra JC, Gonçalves e Silva RH, Savi BM, Marques C, Alarcon OE. New methodology for AC-pulsed GMAW parametrization applied to aluminum shipbuilding, The Brazilian Society of Mechanical Sciences and Engineering, 2015.

[6] Kim TJ, Lee JP, Min BD, Yoo DW, Kim CU. Characteristics of pulse MIG arc welding with a wire melting rate change by current polarity effect. Journal of Electrical Engineering \& Technology. 2007;2(3):366-372. http://dx.doi.org/10.5370/JEET.2007.2.3.366.

[7] Talkington J. Variable polarity gas metal arc welding [MSc dissertation]. Ohio: The Ohio State University; 1998.

[8] Okumura T, Taniguchi C. Engenharia de soldagem e aplicações. Rio de Janeiro: LTC Editora; 1982. p. 461.

[9] Masubuchi K. (1980). Analysis of welded structures: residual stresses, distortion, and their consequences. Londres: Pergamon Press Ltda. 
[10] Radaj D. (1992). Heat effects of welding: temperature field, residual stress, distortion. Berlin: Springer. http://dx.doi.org/10.1007/978-3642-48640-1.

[11] Hidayat MIP, Syahroni N. 3D finite element simulation of t-joint fillet weld: effect of various welding sequences on the residual stresses and distortions, numerical simulation - from theory to industry. Rijeka: InTech; 2012.

[12] Amaral MAD. Imperfeições de fabricação na construção naval e offshore [Tese de doutorado]. Rio de Janeiro: Escola Politécnica, Universidade Federal do Rio de Janeiro; 2006.

[13] Amaral MAD, Estefen SF. Distorções de fabricação na construção naval e offshore. In Anais do $3^{\circ}$ Congresso Brasileiro de P\&D em Petróleo e Gás; 2005; Salvador-BA. Salvador: Instituto Brasileiro de Petróleo e Gás (IBP)/UNIFACS; 2005. p. 6.

[14] American Welding Society - AWS. Welding handbook - welding science aBAnd technology. 9th ed., Vol. 1. Miami: Welding Handbook Committee; 2001.

[15] Box GEP, Draper NR. Empirical model building and response surfaces. New York: John Wiley \& Sons, Inc.; 1987.

[16] Myers RH, Montgomery DC. Response surface methodology. 2nd ed. New York: John Wiley \& Sons, Inc.; 2002.

[17] Box GEP, Behnken DW. Some new three level designs for the study of quantitative variables. Technometrics. 1960;2(4):455-475. http://dx.doi.org/10.1080/00401706.1960.10489912.

[18] Montgomery DC. Design and analysis of experiments. 8th ed. USA: John Wiley \& Sons, Inc.; 2013.

[19] Ferreira SLC, Bruns RE, Ferreira HS, Matos GD, David JM, Brandão GC, et al. Box-Behnken design: an alternative for the optimization of analytical methods. Analytica Chimica Acta. 2007;597(2):179-186. http://dx.doi.org/10.1016/j.aca.2007.07.011. PMid:17683728. 